\title{
Floating the invisible swan: noninvasive prediction of haemodynamics
}

\author{
Vineet Agrawal and Evan L. Brittain \\ Affiliation: Division of Cardiology, Dept of Medicine, Vanderbilt University Medical Center, Nashville, TN, USA.
}

Correspondence: Evan L. Brittain, 2525 West End Ave, Ste 300-A, Nashville, TN 37203, USA.

E-mail: evan.brittaindvumc.org

@ERSpublications

The study by Obokata and co-workers published in this issue of the European Respiratory Journal significantly contributes to the field of noninvasive prediction of haemodynamics during exercise http://bit.ly/2svY7TP

Cite this article as: Agrawal V, Brittain EL. Floating the invisible swan: noninvasive prediction of haemodynamics. Eur Respir J 2020; 55: 1902385 [https://doi.org/10.1183/13993003.02385-2019].

Pulmonary hypertension $(\mathrm{PH})$ describes a heterogeneous set of diseases associated with increased morbidity and mortality, regardless of the aetiology [1-4]. The gold standard for diagnosing and phenotyping $\mathrm{PH}$ remains invasive measurement via right heart catheterisation [5]. Noninvasive estimation of pulmonary haemodynamics is an attractive alternative to reduce procedural risk and to more broadly study patient subsets who do not uniformly undergo right heart catheterisation for evaluation of $\mathrm{PH}(e . g$. most patients with $\mathrm{PH}$ due to left heart disease) [5-7]. However, imperfect correlations between invasive and noninvasive measurements limit broad adoption of noninvasive strategies for the evaluation of $\mathrm{PH}$ [8-13].

In this issue of the European Respiratory Journal, Овоката et al. [14] identified an important contributor to the noninvasive estimation of pulmonary artery (PA) pressure with exercise: right atrial (RA) hypertension. In their study of 97 patients who underwent simultaneous collection of echocardiographic estimates and invasive measures of haemodynamics, the authors showed a moderate-to-strong correlation between invasive measurements and noninvasive estimates of PA pressure, right ventricle (RV) to PA gradient, and RA pressures at rest. In agreement with previous studies, Bland-Altman analysis of their data confirmed minimal bias between invasive and noninvasive measurements despite large limits of agreement $[15,16]$. In other words, noninvasive estimates performed well on a population level but individual level correlations were weaker, which introduces important concerns for misclassification. At peak exercise, echocardiographic measures consistently underestimated true PA pressure estimates (by 3-6 $\mathrm{mmHg}$ on average), largely driven by underestimation of RA pressure during exercise (by $5 \mathrm{mmHg}$ on average). In contrast, the measurement of the RV-PA gradient (i.e. tricuspid regurgitation peak velocity) correlated with invasive measurements with almost no bias ( $\mathrm{r}=0.73,0-1 \mathrm{mmHg}$ bias), suggesting this measure in isolation may be the most valuable for identifying patients with elevated pulmonary pressures noninvasively. Of note, these findings were limited by the ability to estimate PA systolic pressure in only $16 \%$ of patients during exercise, largely driven by the inability to visualise the inferior vena cava.

The work by Овоката et al. [14] has two important implications. The first is that their work highlights the importance and under-recognised contribution of RA hypertension to the development of exercise-induced $\mathrm{PH}$. Recent studies have identified RA dysfunction as both prevalent and prognostically important in patients with World Health Organization (WHO) group $1 \mathrm{PH}$ [17]. However, detailed pathophysiological study of exercise-induced $\mathrm{PH}$ has been hampered by the lack of consensus regarding thresholds for diagnosis, the variability in protocols utilised for exercise, and the invasive nature of the 
study required for diagnosis [18]. Although Овоката et al. [14] contribute to the known literature by showing similar abnormalities in the RA in their subset of patients highly enriched for WHO group $2 \mathrm{PH}$, the broadly generalisability of this finding to all subsets of patients with either exercise-induced or resting $\mathrm{PH}$ remains unclear. Furthermore, since elevations in RA pressure can occur through various mechanisms (post-capillary venous hypertension and increased back flow, increased pericardial restraint or pressure, abnormalities in RV-PA coupling, or primary abnormalities of RA function), replication of the findings by Овоката et al. [14] is necessary to understand the role of RA pressure and function in all subsets of patients with $\mathrm{PH}$.

The second implication of this important work by Овоката et al. [14] is the finding that noninvasive estimation of RA pressure poorly correlated with and consistently underestimated true RA pressure using the standard American Society of Echocardiography methods for estimating RA pressure [19]. This bias was notably mitigated, but not eliminated, by using a modified Mayo Criteria for RA pressure estimation. As noted by the authors, the discrepancies between invasive and noninvasive PA pressure estimates was almost entirely accounted for by discrepancies in RA pressure estimate, a finding that may explain previous discrepancies between invasive and noninvasive haemodynamic measures [8-13]. This finding highlights a call to action to identify better noninvasive methods of estimating RA pressure. In addition to refining noninvasive haemodynamic measurements of pulmonary and post-capillary pulmonary pressures, measurement of RA pressure has clear implications for everyday practice (e.g. jugular venous pressure estimation). On a population level, most patients at risk for exercise-induced PH or RA hypertension (i.e. patients with heart failure or COPD) do not routinely undergo invasive right heart catherisation, thus making accurate noninvasive estimates even more important.

Finally, the study by Овоката et al. [14] contributes to the growing literature that has demonstrated the feasibility of population-level noninvasive estimations of haemodynamics $[15,16]$. Key gaps in our understanding of the pathophysiology of pulmonary vascular disease and inconsistent translation from pre-clinical models to patients has led to a greater interest in the use of large patient-derived datasets for gaining insight into the pathogenesis of pulmonary vascular disease [20,21]. Additionally, exercise studies are challenging, require specific expertise, and are not performed at all centres. These limitations have led to inconsistent understanding of the clinical, biological and prognostic implications of altered haemodynamics during exercise [22, 23]. Aggregate data utilising noninvasive measures would not only include subsets of populations that otherwise would not be included in studies limited to invasively measured haemodynamics, but also ultimately help to standardise the technique of assessing exercise-induced PH. Fortunately, large scale efforts are already ongoing through the "pulmonary haemodynamics during exercise - research network" (PEX-NET) to address the current lack of standard in exercise pulmonary haemodynamics based on invasive haemodynamics [24]. Findings from the PEX-NET research network will only further inform adequate endpoints in noninvasive estimation of haemodynamics during peak exercise.

In summary, the authors are congratulated on a study that has clear clinical implications. In addition to identifying RA hypertension as an important contributor to exercise-induced $\mathrm{PH}$, their work also raises awareness that exercise-induced $\mathrm{PH}$ may be underdiagnosed due to underestimation of noninvasive estimates of RA pressure. Beyond identifying future avenues of investigation to improve noninvasive prediction of invasive haemodynamics, their work also paves the way to utilising vast and growing data from real world populations to study the pathophysiology of cardiopulmonary disease.

Conflict of interest: V. Agrawal has nothing to disclose. E.L. Brittain has nothing to disclose.

\section{References}

1 Aronson D, Eitan A, Dragu R, et al. Relationship between reactive pulmonary hypertension and mortality in patients with acute decompensated heart failure. Circ Heart Fail 2011; 4: 644-650.

2 Khush KK, Tasissa G, Butler J, et al. Effect of pulmonary hypertension on clinical outcomes in advanced heart failure: analysis of the Evaluation Study of Congestive Heart Failure and Pulmonary Artery Catheterization Effectiveness (ESCAPE) database. Am Heart J 2009; 157: 1026-1034.

3 Alushi B, Beckhoff F, Leistner D, et al. Pulmonary hypertension in patients with severe aortic stenosis: prognostic impact after transcatheter aortic valve replacement: pulmonary hypertension in patients undergoing TAVR. JACC Cardiovasc Imaging 2019; 12: 591-601.

4 Manes A, Palazzini M, Leci E, et al. Current era survival of patients with pulmonary arterial hypertension associated with congenital heart disease: a comparison between clinical subgroups. Eur Heart J 2014; 35: 716-724.

5 Galiè N, Humbert M, Vachiery J-L, et al. 2015 ESC/ERS Guidelines for the diagnosis and treatment of pulmonary hypertension. Eur Respir J 2015; 46: 903-975.

6 McLaughlin VV, Archer SL, Badesch DB, et al. ACCF/AHA 2009 Expert Consensus Document on Pulmonary Hypertension. J Am Coll Cardiol 2009; 53: 1573-1619.

7 Hernandez GA, Lemor A, Blumer V, et al. Trends in utilization and outcomes of pulmonary artery catheterization in heart failure with and without cardiogenic shock. J Card Fail 2019; 25: 364-371. 
8 Yock PG, Popp RL. Noninvasive estimation of right ventricular systolic pressure by Doppler ultrasound in patients with tricuspid regurgitation. Circulation 1984; 70: 657-662.

9 Kitabatake A, Inoue M, Asao M, et al. Noninvasive evaluation of pulmonary hypertension by a pulsed Doppler technique. Circulation 1983; 68: 302-309.

10 Masuyama T, Kodama K, Kitabatake A, et al. Continuous-wave Doppler echocardiographic detection of pulmonary regurgitation and its application to noninvasive estimation of pulmonary artery pressure. Circulation 1986; 74: 484-492.

11 Janda S, Shahidi N, Gin K, et al. Diagnostic accuracy of echocardiography for pulmonary hypertension: a systematic review and meta-analysis. Heart 2011; 97: 612-622.

12 Rich JD, Shah SJ, Swamy RS, et al. Inaccuracy of Doppler echocardiographic estimates of pulmonary artery pressures in patients with pulmonary hypertension: implications for clinical practice. Chest 2011; 139: 988-993.

13 Fisher MR, Forfia PR, Chamera E, et al. Accuracy of Doppler echocardiography in the hemodynamic assessment of pulmonary hypertension. Am J Respir Crit Care Med 2009; 179: 615-621.

14 Obokata M, Kane GC, Sorimachi $\mathrm{H}$, et al. Noninvasive evaluation of pulmonary artery pressure during exercise: the importance of right atrial hypertension. Eur Respir J 2020; 55: 1901617.

15 D'Alto M, Romeo E, Argiento P, et al. Accuracy and precision of echocardiography versus right heart catheterization for the assessment of pulmonary hypertension. Int J Cardiol 2013; 168: 4058-4062.

16 Agrawal V, D'Alto M, Naeije R, et al. Echocardiographic detection of occult diastolic dysfunction in pulmonary hypertension after fluid challenge. J Am Heart Assoc 2019; 8: e012504.

17 Alenezi F, Mandawat A, Il'Giovine ZJ, et al. Clinical utility and prognostic value of right atrial function in pulmonary hypertension. Circ Cardiovasc Imaging 2018; 11: e006984.

18 Medarov BI, Jogani S, Sun J, et al. Readdressing the entity of exercise pulmonary arterial hypertension. Respir Med 2017; 124: 65-71.

19 Rudski LG, Lai WW, Afilalo J, et al. Guidelines for the echocardiographic assessment of the right heart in adults: a report from the American Society of Echocardiography. J Am Soc Echocardiogr 2010; 23: 685-713.

20 Brittain EL, Chan SY. Integration of complex data sources to provide biologic insight into pulmonary vascular disease (2015 Grover Conference Series). Pulm Circ 2016; 6: 251-260.

21 Hemnes AR, Beck GJ, Newman JH, et al. PVDOMICS. Circ Res 2017; 121: 1136-1139.

22 Kovacs G, Berghold A, Scheidl S, et al. Pulmonary arterial pressure during rest and exercise in healthy subjects: a systematic review. Eur Respir J 2009; 34: 888-894.

23 Kovacs G, Olschewski A, Berghold A, et al. Pulmonary vascular resistances during exercise in normal subjects: a systematic review. Eur Respir J 2012; 39: 319-328.

24 Kovacs G, Herve P, Olschewski $H$. The pulmonary haemodynamics during exercise - research network (PEX-NET) ERS Clinical Research Collaboration: investigating the prognostic relevance of exercise haemodynamics. Eur Respir J 2019; 53: 1900458. 